Journal of Social Sciences 8 (3): 447-453, 2012

ISSN 1549-3652

(C) 2012 Science Publications

\title{
Religion and Schools in a Liquid World
}

\author{
Frank Peters \\ Department of Educational Policy Studies, \\ Faculty of Education, University of Alberta, Edmonton, T6G 2G5, Canada
}

\begin{abstract}
This study is an exploration of the changing contexts within which schools are required to function. As global borders have become more porous schools are challenged to deal with students from increasingly diverse cultural, linguistic and religious backgrounds, frequently in a political context that is explicitly secular or nondenominational. This perspective may not be perceived by all to be as "neutral" as is sometimes claimed. Our ever-developing technologies, more accessible than ever before, have eliminated many knowledge barriers and created unprecedented awareness of global movements and events. Fewer people live isolated from world affairs and this increased knowledge has created a greater sensitivity to human rights. A heightened "rights consciousness" has emerged, leading to demands in the areas of education, religion, tolerance and the manner in which these constructs are dealt with in schools. There is a growing awareness of the geopolitical dangers associated with fundamentalism, whatever their origins. This is allied to an appreciation that an educated populace contributes significantly to not only the economic well-being of individual nations but also exhibits the deeper knowledge and understandings essential to peace and harmony between peoples of differing backgrounds and diverse religious values and beliefs. In our attempts to further democracy, respect pluralism and develop more open and tolerant communities what policies will best inform practice in our schools? How can we prepare and support teachers and administrators so that the underlying values of these policies can be practiced and taught in our schools?
\end{abstract}

Key words: Negative globalization, consumption, disengagement, Intolerance, capabilities

\section{INTERDECUTION}

Over a decade ago the term "liquid" first appeared as a descriptor that might appropriately be applied in our attempts to capture some of the key elements of our emerging "post" postmodern society. First used by Zygmunt Bauman as a metaphor for our current world, he and others have used it extensively and influentially since the publication of Liquid Modernity in 2000. Smith (2010) points out that the flexibility and richness of the construct, among other characteristics, make it especially useful in our attempts to identify the defining features of our current-day society and the unique challenges that emerge as a result of how our society has emerged and configured itself. "Liquid modernity' is an idea that penetrates quickly into the reader's mind. It is a profound and brilliant concept, both flexible and fertile" (p. 7).

The central element (if it can be called that) of our "liquid" world is, according to Abrahamson (2004) its "lack of stable institutions. There is no condition; everything is process" (p. 171). The world that Bauman describes is one in which barriers have been broken down and disappeared. For many, this provides a sense of freedom and empowerment and liberation. Bauman however focuses specifically on the problems that the removal of traditional structures creates. The traditional structures provided security and predictability that made it easier for many to cope. Furthermore he points out that essentially their disappearance should not be linked to any social movements across the world but rather to the need for the utmost flexibility in the money markets.

In today' world, which focuses primarily on consumption and consuming, there must be as little regulation as possible, as little constraint as possible to the free flow of capital and goods and services, if the neoliberal, consumerist dream is to be realized. Bauman's writings since the turn of the century invite us to examine and critique what he and others frequently refer to as "negative globalization," the hurtful and harmful consequences of globalization and the impact that it is having on the lives of countless millions around the world.

Bauman's writings and thinking have always been focused on "the human consequences' of social development. He is concerned with the concrete and often merciless repercussions on those whose lives are 


\section{J. Social Sci., 8 (3): 447-453, 2012}

most severely affected by social transformations and in his descriptions he staunchly remains on the side of those marginalized, hurt or excluded" (Jacobsen and Poder, 2008). Davis (2008) points out that Bauman's work is not focused on the financial and economic outcomes of globalization, nor on the political processes involved in bringing about our current global society. Rather, he contends that the focus is on "the social, political and ethical dimensions that are manifest in the all-too-human consequences of its [globalization's] world-wide impact" (p. 137). Smith (2010) tells us that consistently, Bauman's “deepest moral, political and intellectual concerns relate to the social and institutional conditions under which human beings may enjoy individual responsibility, equality and justice" (p.1).

The term, "liquid modernity" is now used as a descriptive, rich, incisive and profound marker, an can be broken down into its constitutive elements which can then be considered in terms of their individual and collective impacts on the everyday lives of peoples across the world. Some, like Lee (2005) will find it an "apt term for making sense of changes as well as continuity in modernity" (p. 61). Jacobsen and Marshman (2008) point out that Bauman uses metaphors (such as liquidity) "as a device to recall us to our common humanity, as a means of reawakening our sense of responsibility for the Other and of human possibility" (p. 21).

Today's world: Bauman insists that concentrating on the capacity for liquids to "flow. . . is a trivial, even banal observation" (Gane, 2004). "What sets liquids apart from solids is the looseness and frailty of their bonds" (p.5). He points us to the "intrinsic inability of fluids to hold their shape for long on their own," and to the fact that a continuous and irreversible change of mutual position of parts can be triggered by even the weakest of stresses" (p. 5). He tells us that "used as a metaphor for the present phase of modernity 'liquid' makes salient the brittleness, breakability, ad hoc modality of inter-human bonds" (p.5).

In the initial stages of modernity society attempted to put in place structures that were both solid and fixed However in today's world we are faced with "the continuous and irreparable fluidity of things" (Gane, 2004). This is linked to a state where everything is process. Relationships are continually and "progressively elbowed out and replaced by the activity of "relating", (p. 3). The fact that process replaces all fixed structures, is central to Bauman's more recent writings and he sees it as a critical descriptor of today's world. "All modernity means incessant, obsessive modernization (there is no state of modernity; only a process" (p. 3). "Bonds" he tells us, "are easily entered but even easier to abandon. Much is done (and more yet is wished to be done) to prevent them from developing any holding power; long-term commitments with no option of termination on demand are decidedly out of fashion and not what a 'rational chooser' would choose" (p.3). In an earlier work, when commenting on the nature of our consumer society had warned Bauman (1998) that all agreements, oaths, commitments should come with an "until further notice" (p. 81) proviso included.

This capacity for disengagement is a central technique of liquid modernity. In essence it permits international corporations and individual traders to disengage from a location or a market with little or no notice and regardless of the negative consequences that such actions might have on the broader communities. This is tied to the globalization of both markets and labor and provides manufacturers with the freedom to produce their goods where and how this can be accomplished most economically-that is with the least expenditure of capital. This may entail physical removal of a plant, or a shut-down, temporarily or permanently, disengagement from sectors of the workforce, introduction of temporary work-forces from wherever suitable (cheaper) employees can be found, or any combinations of the above. Heine and Thakur (2011) warn us that "labour rights have been less assiduously protected than capital and property rights and the global rules on trade and finance are unfair to the extent that they produce asymmetric effects on rich and poor countries" (p.3). Their pertinent comments may be relevant in many "rich" or developed countries as well as in poorer ones, as worker rights are massively eroded in developed countries in the name of 'economic recovery or ensuring that corporations and sectors critical to sustaining the GDP or the GNP do not exercise their threats of disengagement, threats which can often be sufficient to produce favorable conditions for greater profit, but can be demoralizing, dehumanizing and unfair from a social perspective. This point is also taken up forcefully by Zizek (2009).

A critical element in the shift from "modern" to late or post "postmodern" society is the move from production to consumption. Today's society, according to Bauman (1998) "needs to engage its members in their capacity as consumers" (p. 80). He suggests to us that whereas in previous generations philosophers and others would deliberate on whether one worked to live or lived to work, today's conundrum $d u$ jour would centre on "whether one needs to consume in order to live or whether one lives so that one can consume" (pp. 


\section{J. Social Sci., 8 (3): 447-453, 2012}

80,81). The emergence of consumption as a dominating element in our society has not come about by accident. We live in the "age of persuasion" to repeat the title of a $\mathrm{CBC}$ radio show. Our consumption is relentlessly cultivated by a constant barrage of advertising that tells us how we should order every instant of our lives. As Bauman and others have reminded us our sense of our identity has shifted from our understanding of who we are and what we contribute to what we consume-where we live, what we wear, what we drive, where we vacation, where we dine.

One can see this uber-consumption as an inevitable outcome of the expansion of the market economy, integral to the neo-liberal project lunched in the 1980s. If the market is to be the central generator of prosperity and wealth and national as well as individual wellbeing, then there must be purchasers of whatever it is the market is selling, whether that be houses, health, education, fine art works, haute cuisine or space travel. And while there may be a constant market for staple goods, the market itself and its branch plants in the advertising sectors, will create niche needs in order to ensure that its goods are perceived as being required and purchased. Statistics relating to the extent of personal and household debt, in almost all countries in what is called the developed world, demonstrate just how successful the market has been in convincing huge numbers of consumers that they cannot do without the very latest version of those products that the same market sold to them only months previously. The market is about selling and consumers are essential to the ability of any market to sustain itself.

In looking at today's world in terms of the social structures and how these impact individual lives it may not be necessary to attempt to establish any causal relationships. In that the neoliberal project requires effective markets in order to be successful, a globalized world, as free as possible from any restrictions and regulations is to be desired. This world will evolve into the "liquid world" of which Bauman writes so clearly and whose impact he so graphically describes. The extent to which huge sectors of the world's population bought into the neoliberal lingua franca of the marketplace may be seen by the fact that regulatory authorities and governments across the world permitted and in many cases were complicit in the greed and incompetence of the banks and property developers during the recent economic collapse of 2008. Those who were in a position to prevent the chaos which arose from the virtually regulation-free environment did nothing and the rest of the world basked in a climate in which it would have been difficult to call a halt to the excesses in borrowing, consuming and speculating.
The difficulties that inhabitants of the liquid world must struggle with are the inevitable outfall of the down-side of globalization, what Bauman calls "negative globalization." The widespread unresponsiveness and insensitivity to the relationship between many of the dilemmas created by the manner in which we have gone about development and the problems that have emerged in many sectors of society, create immense challenges on a global scale for civil society and for agencies involved in any type of social service programming, such as health, education, human rights development, peace-keeping or making, or community development.

Heine and Thakur (2011) describe vividly how globalization has created "losers as well as winners" (p. 3 ) and comment, in an almost irrelevant aside that "the problems lie not in globalization per se, but in the 'deficiencies in its governance' (World Commission of Globalization 2004: xi)" (p. 3). They speak of the fact that even before the financial downturns experienced in the years after 2008 many countries were expressing concerns that their cultural and social integrity as well as their economic sovereignty were being jeopardized. Weaker, poorer, less-developed and even smaller countries were not on an equal footing with larger, more developed countries in terms of their overall vulnerability and exposure to transnational market forces. While the authors acknowledge the immense value of the developments in technology and specifically the internet, in bettering the lives of countless poorer people across the world, they have also "let loose the infrastructure of uncivil society" (p. 4) on the world. They inform us that "uncivil society" is a portmanteau term for a wide range of disruptive and threatening elements that have emerged in the space between the individual and the state and that lie outside effective state control" (p. 4).

The gaps between the rich and the poor have widened, in many places sharply and this increased inequality is evident both between and within countries and nations. As Heine and Thakur (2011) point out this "deepening of poverty and inequality-prosperity for a few countries and people, marginalization and exclusion for many-has implications for social and political stability, again among as well as within states" (p. 3). Cumulatively, one of the most evident outcomes of the negative, uncivil products of globalization is a massive increase in the numbers of those living in constant fear (Bauman, 2006). The fear can be caused or attributed to any one or any number of the features associated with liquid modernity and negative globalization. It can be based in the uncertainties associated with the disappearance of traditional structures that once gave our lives security and some 


\section{J. Social Sci., 8 (3): 447-453, 2012}

degree of predictability. We may be faced with a life of poverty with little or no hope of a better future, a sense of hopelessness and victimization at the inevitability and inexorability of the global forces utterly beyond our control and apparently beyond the control of the governments under whom we live. The fear may be based in the fact that we live in a location that is a centre of illegal activity of one sort or other, exposing me and those close to me to constant danger and constant vulnerability. My fears may be based in the concerns I have with the changed nature of the relationships between the corporate sector and 'place;' the realization that nothing ties my employers to me and my community other than the fact that it is financially beneficial for them to be where they are now. Should any change occur in that relationship I may be unemployed and even unemployable, discarded, disposed of as "surplus to need." The fear may be based in any combination of these or other factors that have been exacerbated and elevated in both their consequences and in their frequency by the changed nature of our global, liquid society. Zizek (2009) points to the "fear of external social life itself" (p. 4) that is a constant factor in the lives of the superrich.

Disengagement and Re-engagement: The challenge to escape from fear, poverty, insecurity, oppression is an attraction presented via today's media to peoples all over the world. There is an apparently open invitation to seek a better life in a better world, primarily through consumption but fundamentally through the exercise of choice. One can choose to set aside the constraints of the life that is now perceived as being a burden or dangerous or precarious in some way. There is far greater mobility available to people today than at virtually any time in history. While there are greater restrictions on immigration to many developed countries today than there were in the early years of the decade, as a result of the hobbled nature of economies globally, it is still possible for certain classes of persons to move from one location to another, with or without support and depending on whether they meet the now more stringent regulatory requirements of the receiving country. Nonetheless the inescapable fact is that there are far greater numbers of peoples living outside the lands of their births today than at any previous time in history. This has been facilitated by the liquid nature of our modern society but it should not be assumed that it has necessarily lessened the burdens of poverty and inequality in the world.

Nor has the marketplace been neutral in terms of creating the appetites for wandering. It promises more to everybody regardless of whether they have plenty or little. At its core it promotes itself as offering "more" than one already has, whether this is a subsistence job or security within a gated community. The wandering to which Bauman (1998) has been nurtured by the advanced media technologies that promise more and better and different to virtually every sector of society. With the growing fear that speaks of Bauman (2006) it is inevitable that large masses of peoples will attempt to find an escape to security and a better life.

Those who uproot and move from place to place may frequently bring little or no physical belongings with them. Nonetheless they bring with them their cultural and historical presence and identity that in many cases is deeply infused with specific religious values and traditions. For many these religious beliefs are among the few surviving ties that they can bring with them to their new homes. Their religious values may have been challenged and modified by the portrayals of the materialistic cultures available through the media but the depths of their roots and the intertwinedness of their everyday lives with matters of a religious nature may be one of the few certainties and stable elements that provide some modicum of security in the emergent liquid world of choice and consumption and instability and transience. The better life that many of them dream of is one where they will be able to exercise their religion freely, carry on those cultural traditions that they consider sacred, have their children receive an education in accordance with the values that they prize and wish to nurture and where they and their families will be given a chance to access the worldly riches and worldly goods unavailable to them in the country they are leaving. For many who seek refuge or hope in a foreign and challenging environment their expectations in relation to their ability to practice their religion may be every bit as critical as their hopes for security, stability and a more prosperous life. They wish to pursue the dream of unlimited choice held out to all vagabonds, nomads and travelers (to use Bauman's terms) and at the same time maintain their own cultural, linguistic and spiritual identities. This is the promise that our advertising of multicultural and pluralistic acceptance holds out.

Secularism and religions: Charles Taylor (2010) tells us that "it is generally agreed that modern democracies have to be 'secular"' (p. 23). He points out that the "issues concerning secularism have evolved in different Western societies in recent decades because the faiths represented in those societies have changed" (p. 24). In other words states are challenged in ways not usual in previous generations, by having within them significant numbers of peoples of different faiths or of none. The security associated with a comparatively homogenous belief base among the largest sector of society, as was the norm throughout most of Europe until the second half of the 20th century, has disappeared. The former 


\section{J. Social Sci., 8 (3): 447-453, 2012}

uniformity has been replaced with a diversity and a pluralism that incorporates notable diversity among religious beliefs and traditions as well as an increasing number that would identify as secular rather than be affiliated with any specific religion or religious tradition. Taylor argues that the role of the state in these complex and diverse times must be to adopt a position that protects all residents in the "practice of whatever outlook they choose or find themselves in" (p. 25). It is not the role of the state to favor a religious position over a non-religious one, any more than it should favor one particular religion over another. "There is no reason to single out religious (as against nonreligious), "secular" (in another widely used sense), or atheist viewpoints. Indeed, the point of state neutrality is precisely to avoid favoring or disfavoring not just religious positions, but any basic position, religious or nonreligious. We can't favor Christianity over Islam, but also we can't favor religion over against nonbelief in religion, or vice versa" (p. 25).

Taylor's neatly draws together many of the challenges faced by both new immigrants and settled residents in today's world. On the one hand there is the fear that we encounter when we come face to face with the "other" in terms of background, beliefs and traditions. We feel threatened and we are tempted to demand conformity to what we perceive to be "our way of life." Or we may opt for a compliance with a strictly secular belief structure, assuming that this orientation is neutral and therefore not privileging any particular belief or creed. Frequently, as is evident in so many of the emerging responses to dealing with heretofore eventualities, we respond in a defensive and at the same time aggressive fashion that would be contrary to the approach presented to us by Smith (2010) in explaining how Emmanuel Levinas would encourage us to respond: "Levinas insists that we should recognise the Other (other people, other cultures, other ways of life and so on) as irreducibly strange, different and beyond our comprehension. We should not try to dominate, destroy or change the Other. Instead, we should recognise the challenge the Other's existence presents to our taken-forgranted habits and self-satisfied sense of ourselves. We have the freedom to either reject or respond positively to the Other, especially when it is weak and in need. If we respond positively, this should not be in the expectation of reciprocity or recompense but simply because we feel an obligation, a sense of responsibility without clear limits" (p. 4). The strangeness or the differences are no excuse for not accepting the challenges to recognize the humanness of the other, as he or she is, in the completeness of his or her identity.

Bauman (2000) refers to the sentiments expressed by Levinas and draws extensively from the work of
Gadamer (1995) who placed diversity and the wealth of variety above all the cultural values to be found in Europe. Bauman comments that, "The abundace of diversity is deemed by him (Gadamer) the most precious treasure Europe has managed to save from the conflagrations of the past and offer to the world today. 'To live with the Other, live as the Other's Other, is the fundamental human task-on the most lowly and the most elevated levels alike . . . Hence perhaps the particular advantage of Europe, which could and had to learn the art of living with others.' (p, 84). Bauman continues, drawing frequently on Gadamer, "In Europe, 'Another' is the closest neighbour and so Europeans must negotiate the conditions of this neighbourhood despite the differences which divide them. The European landscape, says Gadamer, characterized as it is by 'the multilingualism, the close neighbourhood of the Other and equal value accorded to the Other, in a space tightly constrained, can be seen as a research laboratory, or a school, from which the rest of the world can carry away the knowledge and skills which determine our survival or doom'. 'Europe's task', says Gadamer, consists of passing on to all the art of everyone learning from everyone" (p. 84). Whether Gadamer's assessment of the European scenario is accurate is really irrelevant and would certainly be subjected to careful scrutiny in terms of today's challenges. What is important is the value that both he and Bauman attribute to specific virtues of respect for diversity and multiculturalism and multilingualism.

The invitation or challenge extended by Levinas and Gadamer and taken up by Bauman has clearly been overlooked or rejected in so many countries in recent years in favor of what is a more simple or simplistic approach which, unfortunately is also more demeaning, dehumanizing and victimizing. As Grayling (2009) points out, this may be based in our obsession with efficiency and in our uncontrollable need to find " "simple and absolute' solutions to problems" (p. 199). We cannot ignore the significant and well-publicized evidences of intolerance when faced with how to deal with the other. Some of these responses stem from deep-seated religious convictions as in the case of the twelve year old boy who wore a Tee-shirt to school in Ohio in 2004 proclaiming that "Homosexuality is a sin, Islam is a lie, abortion is murder." Some issues are just black and white" Court Sides with Student, 2005. The Global News Service of the Jewish People Reported (2010) that "fifty clerics" had urged the European Council "to protect their freedom of religion at a time when some right-populist parties are calling for bans to certain non-Christian religious practices, including circumcision for minors and kosher and halal 


\section{J. Social Sci., 8 (3): 447-453, 2012}

butchering of meat. The statement urges that steps be taken to "ensure that Jews and Muslims are able to practice our respective faiths fully and unimpeded by intrusive, discriminatory and unfair governmental regulations." M before this request to the European Council the European Council had "blasted religious intolerance in Pakistan" as a reaction against the deadly penalties legislated against anyone found guilty of blasphemy (Catholic Culture). In February 2011 the Quebec National Assembly excluded a group of baptized Sikhs from the Assembly unless they removed their ceremonial kirpans despite the ruling from the Supreme Court of Canada upholding a student's right to wear his kirpan to school. A spokesperson for the Parti Quebecois stated "that while multiculturalism might be a Canadian value, it is not a Quebec value" A new Quebec Value, 2011. Questions are being asked in Ireland as to whether racism and intolerance are being fuelled by the downturn in the economy. The U.S. Member of the House of Representatives, Peter King, has adopted what many perceive to be a virulent antiMuslim McCarthyesque witch-hunt (NYT, 2011). Biondi (n.d.) points out that in Switzerland in 2009 voters banned the construction of minarets! The (O'Brien and Stasi, 2004) report in France, generated considerable disagreement relating to the manner in which it proposed that laïcité, or secularity be dealt with.

As we look for evidence of growing religious intolerance we can find burnings of the Kuran, bombing of churches, gratuitous reproduction of offensive cartoons in the name of freedom of expression, banning of hijabs or burkas, rejection of full membership in the denomination to specific sectors, whether they be women, divorced people, gays and we sometimes feel under no obligation to become informed on any of these issues. In the name of "choice" some governments are allowing parents to "choose" whether their children will learn about sexual orientation, religion or human sexuality in schools. The state has, at times, no apparent interest in ensuring that children come closer to the other through education about the Other's traditions, practices, values or beliefs.

\section{CONCLUSION}

This study arose out of a desire to make more explicit the features of the changed contexts within which schools operate. In addition I wanted to attempt to identify some of the implications of these changes for particular sectors within our societies. My starting point was the questions, "What are the key features of the 'liquid world' of which Bauman speaks and what are the implications for our schools and our communities of their emergence?
From a methodological perspective the major sources of information for the study was the literature dealing with globalization, poverty and human rights. This literature was exmined thoroughly and critically and the study presents a considered review of the issues as well as an invitation to engage in appropriate manners of responding to the identified issues.

Schools are social constructions where the challenges described in the previous pages come together. In today's world educators are required to deal with the ever-increasing diversity brought about by the liquid modernity within which we live. Simultaneously they must deal with the challenges posed by a consumerist culture that elevates choice to the level of a human right while masking to a significant degree its deep roots in a market-driven ideology. Schools, as agents of the state as well as agents acting on behalf of parents and children, are faced with working within the legal structures while balancing the unavoidable demands to deal with all students in a humanizing respectful manner. As educators, the formative challenges that teachers face are to deal respectfully, in a manner in keeping with Levinas' and Gadamer's encouragements, so that all children can develop their unique capabilities and identities fully, in a supportive and enriched environment. The challenges posed by the limited resources, by the fact that some may demand that the schools should be secular places, not in the sense in which Taylor explains it but rather as places where an absence of religion is insisted upon, the fact that not all traditions and practices may be acceptable to everyone, all of these will pose unique difficulties on a daily basis.

Nussbaum (2011) presents us with a particularly interesting approach by inviting us as educators or people involved in human development to adopt a perspective that is rooted in the creation, nurturing and development of capabilities. "Capabilities," she tells us are "the answer to the question "what is this person able to do and to be"" (p. 20). She is emphatic that we must distinguish between internal and combined capabilities and uses the example of free speech. As an internal capability I might have it but it is a barren capability (excusing the oxymoron) if I am never granted the ability or right to exercise that capability. She reminds us that "many people who are internally free to exercise a religion do not have the opportunity to do so in the sense of combined capability, because religious freedom is not protected by the government" (p.22). One might draw clear analogies to students in schools where democracy and freedom of speech and freedom of religion may well be encouraged as "internal" capabilities but given little or no standing as combined capabilities. The implication appears to be clear. Not alone must educators accept that students have rights, they must be encouraged and enabled to exercise those rights. 


\section{J. Social Sci., 8 (3): 447-453, 2012}

Nussbaum is clear in distinguishing capability from functioning and emphasizes the concept of choice in her deliberations. Neither the fasting nor the starving person is eating but only one is exercising a capability. The starving person cannot choose to eat while the fasting person can. Similarly, imposing any specific religious practice on anyone is just as offensive to a perspective based on capabilities as is denying one the right to practice a chosen religion. This is a clear link to the role that Taylor would have the State (and by extension schools as agents of the State) play in nurturing this capability.

There is one area in which Nussbaum is adamant and in her view this consideration should override any consideration of choice. She holds that governments "should not give people an option to be treated with respect and nonhumiliation" (p. 26). A cynic might whisper that this could have serious implications for how we frequently do schooling, but there are more obvious implications for labor practices and how we treat the poor and indigent and other less advantaged sectors in society, such as temporary foreign workers or people illegally in the country.

A human rights approach to developing capabilities among all our people would require that we avoid and prevent interference by others when one is exercising a right; that we provide support and assistance, particularly to younger or less able members of our community as they attempt to exercise their rights; provide as much affirmative support as is needed so that all can enjoy equal benefit of the exercise of their rights. Without structures and established practices to sustain these supports all rights will be reduced to "freedom of thought" and have nothing to do with living one's capabilities.

Nussbaum points out that "people's choices differ and respect for people requires respecting the areas around them within which they make these choices" ( $p$. 107). We must acknowledge the traditions and beliefs and value structures that undergird and permeate the capabilities that individuals develop. Respect for the individual obliges respect for the choices that individual people make, in the area of religion as anywhere else. Teachers cannot avoid the need to develop, inculcate and support the reality and the capability for freedom of cultural and religious expression. In our liquid world the need for and respect for these freedoms is more critical than ever before.

Our changed, globalized, more open, liquid world has created new challenges for us in all sectors of our society. Our schools cannot adopt a neutral position. Educators, as educators for our entire society, must adopt a principled position that acknowledges that we cannot give our own traditions a "privileged" position just because they are ours, nor can we privilege our religious beliefs and practices over other beliefs and practices just because those who practice these religions are more recently arrived than we are. Human dignity and human respect requires that we give equal position to many elements of the cultures and religions of the others who now make up an increasing part of our society. Our diversity in culture and religion enriches us even if it presents us with challenges that at times appear extremely daunting.

\section{REFERENCES}

Abrahamson, P., 2004. Liquid modernity: Bauman on contemporary welfare society. Acta Sociol., 47: 171-179.

Bauman, Z. 2006. Liquid Fear. 1st Edn., John Wiley and Sons, ISBN-10: 0745636799, pp: 200.

Bauman, Z., 1998. Globalization: The Human Consequences. 1st Edn., Columbia University Press, USA., ISBN-10: 023111429X, pp: 136.

Bauman, Z., 2000. Liquid Modernity. 1st Edn., John Wiley and Sons, ISBN-10: 0745624103, pp: 240.

Davis, M., 2008. Freedom and Consumerism: A Critique of Zygmunt Bauman's Sociology. Ashgate, UK, ISBN-10: 0754672719, pp: 198.

Gadamer, H.G., 1995. Das Erbe Europas. 1st Edn., Suhrkamp, Berlin, ISBN-10: 3518220047, pp: 172.

Gane, N., 2004. The Future of Social Theory. 1st Edn., Continuum, London, UK., ISBN-10: 0826470661, pp: 224.

Grayling, A.C., 2009. Liberty in the Age of Terror. 1st Edn., Bloomsbury Publishing, London, UK, ISBN10: 1408802422 , pp: 304.

Heine, J. and R. Thakur, 2011. The dark side of globalization. United Nations University Press, Tokyo.

Jacobsen, M.H. and P. Poder, 2008. The Sociology of Zygmunt Bauman. Ashgate Publishing, UK., ISBN-10: 0754670600, pp: 245.

Lee, R.L.M., 2005. Bauman, Liquid Modernity and Dilemmas of Development. Thesis Eleven, 83: 6177. DOI: $10.1177 / 0725513605057137$

NYT, 2011. Domestic terrorism hearing opens with contrasting views on dangers.

Nussbaum, M., 2011. Creating Capabilities: The Human Development Approach. 1st Edn., Belknap Press of Harvard University Press, ISBN-10: 0674050541, pp: 256.

Smith, D., 2010. Strategic disengagement and sociological hermeneutics.

O'Brien, R. and B. Stasi, 2004. The Stasi Report: The Report of the Committee of Reflection on the Application of the Principle of Secularity in the Republic. Fred B Rothman and Co, Colorado, ISBN-10: 0837735254, pp: 115.

Zizek, S., 2009. First as Tragedy, then as Farce. Verso, New York, USA, ISBN-10: 1844674282, pp: 158. 